\title{
Priming or executive control? Associative priming of cue encoding increases "switch costs" in the explicit task-cuing procedure
}

\author{
GORDON D. LOGAN and DARRYL W. SCHNEIDER \\ Vanderbilt University, Nashville, Tennessee
}

\begin{abstract}
The explicit task-cuing procedure involves presenting a cue that indicates which task to perform on a target. Responses are typically faster when tasks repeat than when they alternate, and this difference is often interpreted as a measure of the time required for executive control processes to change task set. This article suggests that the difference reflects priming of cue encoding when successive cues are identical or associatively related. Subjects responded to task repetitions more quickly when the cue on the current trial was associatively related to the cue on the previous trial (e.g., day $\rightarrow$ night) than when the cues were unrelated (e.g., verb $\rightarrow$ night). Models applied to the time course function-generated by manipulating the interval between the onsets of the cue and the target-showed that the facilitation was due to cue encoding, a process that does not require online executive control.
\end{abstract}

Task switching has become a popular topic in studies of executive control. Subjects are slower and less accurate when they alternate between tasks than when they repeat tasks. These differences- known as switch costs-have been interpreted as measures of executive control processes that reprogram the cognitive system to adopt a new task set (e.g., Logan \& Gordon, 2001; Meiran, 1996; Rogers \& Monsell, 1995). However, this interpretation of switch costs is controversial because the need to reprogram the cognitive system is not the only difference between task alternations and task repetitions. The task set from the previous trial may interfere with performance when tasks alternate and may facilitate performance when tasks repeat (Allport, Styles, \& Hsieh, 1994; Allport \& Wylie, 2000; Waszak, Hommel, \& Allport, 2003, 2004), mimicking the switch costs that would be produced by reprogramming. This article is concerned with a similar alternative interpretation of task-switching performance in the explicit task-cuing procedure. We suggest that switch costs in this procedure reflect priming from related cues, rather than reprogramming.

In the explicit task-cuing procedure, subjects are given a cue on each trial that indicates which task to perform on a target stimulus. Cues are presented in random order,

This research was supported by Grant BCS 0133202 from the National Science Foundation to G.D.L. We thank Julie Delheimer for conducting the experiment and analyzing parts of the data. Correspondence concerning this article should be addressed to G. D. Logan or D. W. Schneider, Department of Psychology, Vanderbilt University, Nashville, TN 37203 (e-mail: gordon.logan@vanderbilt.edu or darryl.schneider@ vanderbilt.edu).

Note-This article was accepted by the previous editorial team, when Colin M. MacLeod was Editor. and trials are sorted into repetitions and alternations post hoc. The interval between the cue and the target (stimulus onset asynchrony, or SOA) is manipulated to control the time at which the subjects can begin to reprogram their cognitive systems for the upcoming task. The explicit task-cuing procedure produces robust switch costs that decrease as SOA increases, suggesting that subjects begin to reprogram their cognitive systems before the target appears (Meiran, 1996).

Recently, Logan and Bundesen (2003, 2004), Arrington and Logan (2004), and Schneider and Logan (2005) proposed an alternative interpretation of performance in the explicit task-cuing procedure. They suggested that performance may reflect a compound stimulus strategy or a compound retrieval cue strategy, in which subjects encode the cue, encode the target, and use them as a joint retrieval cue to pull an appropriate response from memory. In their view, switch costs reflect a cue-encoding benefit from repeated cues. They noted that the explicit task-cuing procedure typically confounds cue repetition with task repetition: When tasks repeat, the cues also repeat; when tasks alternate, the cues also alternate. Switch costs may reflect a benefit in cue encoding when cues repeat, the time required for reprogramming when cues (and tasks) alternate, or both.

To distinguish between these interpretations and remove the confound between cue repetition and task repetition, Logan and Bundesen (2003) conducted experiments in which there were two cues for each task (also see Arrington \& Logan, 2004; Logan \& Bundesen, 2004; Mayr \& Kliegl, 2003; Schneider \& Logan, 2005). Their Experiment 3 used parity and magnitude judgments of single digits, using the cues parity and odd-even for the parity task and the cues magnitude and high-low for the magnitude task (deciding whether a digit was greater than 
or less than 5). This procedure allows three kinds of transitions between trials: cue repetitions, in which the cue and the task both repeat (e.g., odd-even $\rightarrow$ odd-even); task repetitions, in which the cue changes but the task repeats (e.g., parity $\rightarrow$ odd-even); and task alternations, in which the cue and the task both change (e.g., magnitude $\rightarrow$ odd even). Logan and Bundesen (2003) suggested that cue repetition benefits could be assessed by comparing cue repetitions with task repetitions and that reprogramming costs, if there were any, could be assessed by comparing task repetitions with task alternations. They found large differences between cue repetitions and task repetitions (168 msec in one experiment; $95 \mathrm{msec}$ in another) and small differences between task repetitions and task alternations (35 $\mathrm{msec}$ in one experiment; $14 \mathrm{msec}$ in another), suggesting that switch costs were due primarily to cueencoding benefits.

At the same time, Mayr and Kliegl (2003) reported experiments with two cues for each task. Like Logan and Bundesen (2003), they found large differences between cue repetitions and task repetitions (298 msec in one experiment; $204 \mathrm{msec}$ in another), but unlike Logan and Bundesen, they found large differences between task repetitions and task alternations (302 msec in one experiment; $204 \mathrm{msec}$ in another). Mayr and Kliegl interpreted their results as consistent with reprogramming theories of task switching. Specifically, they argued that the difference between cue repetitions and task repetitions reflected facilitation in retrieving the mapping rules for the task from long-term memory and that the difference between task repetitions and task alternations reflected facilitation in applying the mapping rules to the target once it appeared.

Logan and Bundesen (2004) addressed an important procedural difference between the experiments by Logan and Bundesen (2003) and Mayr and Kliegl (2003). Logan and Bundesen (2003) used word cues whose conventional meanings specified the tasks to be performed on the targets, whereas Mayr and Kliegl used letter cues that were assigned arbitrarily to the tasks. Logan and Bundesen (2004) compared meaningful word cues and arbitrary letter cues, replicating Logan and Bundesen's (2003) results with meaningful word cues and Mayr and Kliegl's results with arbitrary letter cues. They interpreted the results in terms of an extended version of the compound retrieval cue strategy: With meaningful word cues, subjects encode the cue, encode the target, and use them as a joint retrieval cue to pull the appropriate response from memory. With arbitrary letter cues, they encode the cue and use it to pull a mediator (e.g., the task name) from memory. Then they combine the mediator with the target to form a joint retrieval cue that pulls the appropriate response from memory. Logan and Bundesen (2004) argued that retrieval of the mediator would be facilitated when the task repeated, because the mediator from the last trial could still be present in short-term memory. With arbitrary cues, cue repetitions would be faster than task repetitions because the cue repeats, and task repetitions would be faster than task alternations because the mediator repeats. Switch costs can be explained without recourse to reprogramming the cognitive system.

The compound retrieval cue strategy explains the difference between cue repetitions and task repetitions, but it does not explain the small but persistent difference between task repetitions and task alternations that often occurs with meaningful word cues. Across experiments, this difference ranges in magnitude from -2 msec (Logan \& Bundesen, 2004) to $69 \mathrm{msec}$ (Arrington \& Logan, 2004). Schneider and Logan (2005) noted that meaningful word cues assigned to the same task are semantically related, so they may prime each other on task repetition trials. For example, encoding of high-low may be facilitated by prior encoding of magnitude because they are semantically related and episodically associated. Meaningful word cues assigned to different tasks would not be related semantically or episodically, so they should not prime each other; encoding of high-low should not be facilitated by prior encoding of parity. These semantic or associative priming effects on task repetition trials should be smaller than the repetition priming effects on cue repetition trials, so task repetitions should be slower than cue repetitions but faster than task alternations. The purpose of our study was to test this priming hypothesis.

The present experiment used four cues for two tasks. The tasks were parity and magnitude judgments of single digits. We used words as cues in order to manipulate the semantic and associative relations between the cues assigned to same and different tasks. We could not use meaningful word cues that named the tasks to be performed, because cues assigned to the same task would necessarily be related semantically and associatively and cues assigned to different tasks would be unrelated semantically and associatively. Consequently, we used word cues that were arbitrarily related to the tasks to be performed. We used four pairs of associated words-day-night, noun-verb, king-queen, and salt-pepper - and we assigned the words in each pair to the same or different tasks on the basis of three cuing conditions manipulated between subjects. In the associated-within condition, both words in an associated pair were assigned to the same task. For example, for some subjects, day and night were assigned to the magnitude task, and noun and verb were assigned to the parity task. In the associated-between condition, the words in an associated pair were assigned to different tasks. For example, for some subjects, day and noun were assigned to the magnitude task, and night and verb were assigned to the parity task. In the unassociated condition, four words from different associated pairs were assigned to the two tasks. For example, for some subjects, day and noun were assigned to the magnitude task, and queen and pepper were assigned to the parity task.

Using two cues for each task allows the three transitions between trials seen in previous experiments: cue repetitions, task repetitions, and task alternations. From previous research, we expected cue repetitions to be faster than task repetitions because repetition priming will speed up the encoding of the repeated cue (Logan \& Bundesen, 
2003; Mayr \& Kliegl, 2003). We expected task repetitions to be faster than task alternations because of mediator repetition. The cues were related arbitrarily to the tasks, so the subjects must retrieve a mediator-possibly, the task name - before they can engage in compound cue retrieval. The mediator repeats on task repetition trials, and retrieval may be sped up by this repetition (Logan \& Bundesen, 2004). We expected task alternations to be slowest because they would not benefit from repeated cue encoding or repeated mediator retrieval.

The effects of cuing condition on transition are the major focus of the experiment, and task repetitions are the most important transitions for our purposes. Cue repetitions are the same in all three cuing conditions: The cue repeats exactly, regardless of what other cues are assigned to the tasks, so the same amount of repetition priming should be observed in each condition. Task alternations involve transitions between unrelated cues for the associated-within and unassociated conditions, so they should not differ between cuing conditions. Task alternations may involve related or unrelated cues in the associated-between condition, and we will examine these differences separately.

Task repetitions are the most important transitions because they allow semantic or associative priming between cues. Task repetitions should be fast in the associated-within condition because the cues on successive trials are semantically and associatively related to each other and this should reduce cue-encoding time (e.g., day should prime night). Task repetitions should be slower in the unassociated condition because the cues on successive trials are not related to each other (e.g., day should not prime noun). Task repetitions may be even slower in the associated-between condition because the cues on successive trials are unrelated to each other but may prime retrieval of an inappropriate mediator (e.g., day may not prime noun, but it may prime night, facilitating retrieval of the task name associated with night and inhibiting retrieval of the task name associated with noun). However, in associative priming, facilitation is usually much stronger than inhibition (Neely, 1991), so there may be little or no difference between task repetitions in the unassociated and associated-between conditions.

Mean reaction times (RTs) in the different transition conditions do not reflect cue-encoding time directly. Instead, they reflect the sum of cue-encoding time, target-processing time, response execution time, and other residual processes, and the contribution of cue-encoding time decreases as SOA increases. In order to extract a measure of cue-encoding time from the RT data, we applied a model developed by Logan and Bundesen (2003) to the time course function. The model assumes that the time course function reflects a probability mixture of two different RT distributions, one slow and one fast. If the cue has not been encoded, then $\mathrm{RT}=\mathrm{RT}_{\text {Base }}+\mu$, where $\mathrm{RT}_{\text {Base }}$ is the asymptotic $\mathrm{RT}$ after cue encoding is finished and $\mu$ is the mean cue-encoding time. If the cue has been encoded, then $\mathrm{RT}=\mathrm{RT}_{\text {Base }}$. The probability that cue encoding is complete at a given SOA depends on the cumulative distribution of cue-encoding times. We assume that cue-encoding time is distributed exponentially, so the cumulative distribution is characterized by a single parameter, $\mu$, which is the mean of the distribution. Thus, $\mathrm{RT}=\mathrm{RT}_{\text {Base }}+\mu$ with probability $\exp [-\mathrm{SOA} / \mu]$ and $\mathrm{RT}=\mathrm{RT}_{\text {Base }}$ with probability $1-\exp [-\mathrm{SOA} / \mu]$. Putting these together,

$$
\mathrm{RT}=\mathrm{RT}_{\text {Base }}+\mu \exp [-\mathrm{SOA} / \mu] .
$$

We used Equation 1 to estimate cue encoding times and base RTs in each condition and to test hypotheses about changes in cue-encoding times across cuing conditions. Our priming hypothesis predicts that cue-encoding time for cue repetitions should be the same for all cuing conditions, that cue-encoding time for task alternations should be the same for all cuing conditions, but that cue-encoding time for task repetitions should be faster in the associatedwithin condition than in the unassociated condition and, possibly, faster in the unassociated condition than in the associated-between condition. We tested these predictions in model fits to data averaged across subjects and in model fits to individual subject data.

We manipulated the intertrial interval (ITI) to separate the effects of the cue from the effects of target processing on the previous trial. If ITI is held constant, SOA is confounded with the interval between successive targets, and it is possible that SOA effects reflect decay of the task set required for the previous trial, rather than cuing effects (Allport et al., 1994). Several investigators have manipulated ITI and SOA separately and have found strong SOA effects over and above the effects of ITI (Arrington \& Logan, 2004; Logan \& Bundesen, 2003; Logan \& Zbrodoff, 1982; Mayr \& Kliegl, 2003; Meiran, 1996; Meiran, Chorev, \& Sapir, 2000). Nevertheless, it is important to show that our semantic priming effects depend on SOA, rather than on ITI, so we manipulated SOA and ITI independently. Transition type, SOA, and ITI were manipulated within subjects, and cuing condition was manipulated between subjects to minimize confusion and retrieval of prior associations between cues and tasks.

\section{METHOD}

\section{Subjects}

A total of 72 subjects ( 24 in each cuing condition) recruited from the general population of Vanderbilt University served in the experiment for partial course credit or monetary compensation.

\section{Apparatus and Stimuli}

The stimuli were displayed in white on a black background on Sony Trinitron monitors controlled by Dell Dimension computers, and responses were recorded from the numeric keypad of a standard keyboard. The targets were the digits 1, 2, 3, 4, 6, 7, 8, and 9, which were $8 \mathrm{~mm}$ high and $5 \mathrm{~mm}$ wide. The cues were the words day, night, noun, verb, king, queen, salt, and pepper, presented in lowercase font. Including ascenders (e.g., d) and descenders (e.g., q), the cue day was $10 \mathrm{~mm}$ high and $15 \mathrm{~mm}$ wide, night was $10 \mathrm{~mm}$ high and $25 \mathrm{~mm}$ wide, noun was $5 \mathrm{~mm}$ high and $18 \mathrm{~mm}$ wide, verb was $7 \mathrm{~mm}$ high and $18 \mathrm{~mm}$ wide, king was $10 \mathrm{~mm}$ high and $18 \mathrm{~mm}$ wide, queen was $7 \mathrm{~mm}$ high and $25 \mathrm{~mm}$ wide, salt was $7 \mathrm{~mm}$ high and $18 \mathrm{~mm}$ wide, and pepper was $7 \mathrm{~mm}$ high and $28 \mathrm{~mm}$ wide. Pairs of cues were selected on the basis of the high bidirectional free association strengths given by Nelson, McEvoy, and Schreiber (1999). Forward association strength is the probability of producing the second word in each pair, given the first, and backward association strength is the 
Table 1

Assignment of Cue Words to Tasks for the Associated-Within, Associated-Between, and Unassociated Cuing Conditions

\begin{tabular}{|c|c|c|c|c|c|}
\hline \multicolumn{2}{|c|}{ Associated Within } & \multicolumn{2}{|c|}{ Associated Between } & \multicolumn{2}{|c|}{ Unassociated } \\
\hline High-Low & Odd-Even & High-Low & Odd-Even & High-Low & Odd-Even \\
\hline king-queen & salt-pepper & king-salt & queen-pepper & king-salt & night-verb \\
\hline king-queen & day-night & king-day & queen-night & king-day & pepper-verb \\
\hline king-queen & noun-verb & king-noun & queen-verb & king-noun & pepper-day \\
\hline salt-pepper & day-night & salt-night & pepper-day & salt-night & queen-verb \\
\hline salt-pepper & noun-verb & salt-noun & pepper-verb & salt-noun & queen-night \\
\hline day-night & noun-verb & day-noun & night-verb & day-noun & queen-pepper \\
\hline
\end{tabular}

probability of producing the first word in each pair, given the second. According to the Nelson et al. (1999) norms, the forward and backward association strengths were .772 and .730 for king-queen, .701 and .695 for salt-pepper, .819 and .686 for day-night, and .690 and .642 for noun-verb. According to the same norms, the association strength between pairs (i.e., the probability of producing a word in any other pair, given a word in one of the pairs) was 0 .

\section{Procedure}

The basic design of the experiment included 8 (targets) $\times 4$ (cues) $\times 5$ (SOAs: $0,100,300,600$, or $900 \mathrm{msec}) \times 2$ (ITIs: 300 or $900 \mathrm{msec})=320$ trials. There were three replications of this basic design, for a total of 960 trials. Each replication was randomized separately for each subject. Trials were sorted into cue repetitions, task repetitions, and task alternations post hoc.

Each subject experienced only one cuing condition. The cues assigned to each task in each cuing condition are presented in Table 1. In the associated-within condition, words from associated pairs were assigned to the same task and were unrelated to the words assigned to the other task. In the associated-between condition, words from associated pairs were assigned to different tasks. Consequently, the two words assigned to a given task were unrelated, but each word was related to one of the words assigned to the other task (e.g., for some subjects, king and salt were assigned to the high-low task, and queen and pepper were assigned to the odd-even task). In the unassociated condition, only one word from each associated pair was assigned to either task, so that none of the words for the same task or for different tasks were related (e.g., for some subjects, king and salt were assigned to the high-low task, and night and verb were assigned to the odd-even task; for other subjects, day and noun were assigned to the high-low task, and queen and pepper were assigned to the odd-even task). Thus, across subjects in the associatedbetween and unassociated conditions, the assignment of words to tasks was counterbalanced. There were six assignments of cues to tasks in each cuing condition (see Table 1), and four subjects in each group received each assignment.

Responses were recorded from the 1 and 3 keys on the numeric keypad. All the subjects used the index finger of their right hand to press the 1 key for high and odd responses and the middle finger of their right hand to press the 3 key for low and even responses.

The subjects were seated in individual testing rooms after providing informed consent. They were given instructions that described the tasks, targets, assignment of cues to tasks, and response-key mappings. They were instructed to respond as quickly as possible without making errors. Reminders about the cue-task and responsekey mappings were posted below the display screen for the duration of the experiment.

A trial began with a fixation display, which consisted of two plus signs (each $5 \mathrm{~mm}$ high and $5 \mathrm{~mm}$ wide, with inside edges separated by $30 \mathrm{~mm}$ ) that appeared above and below the positions occupied by the cue and target. The fixation display was exposed for $500 \mathrm{msec}$ before it was extinguished and immediately replaced by a cue display, in which one of the cue words appeared centered one row below the top plus sign from the fixation display. At a variable SOA after the onset of the cue display, a target appeared immediately below the cue, centered one row above the bottom plus sign from the fixation display. This cue-target display remained onscreen until a response was registered on the computer's keyboard, at which point the display was extinguished and a blank screen was exposed for the duration of the variable ITI. The next trial commenced immediately with the fixation display, and this procedure was repeated for the duration of a block of trials. The subjects completed 960 trials and were allowed to take breaks every 96 trials.

\section{RESULTS}

The first trial of each block and trials with RTs exceeding $5,000 \mathrm{msec}$ were excluded from the analyses $(1.1 \%$ of all the trials). Trials with incorrect responses were excluded from the RT analysis (3.0\% of all the trials). Transitions (cue repetitions, task repetitions, and task alternations) were determined post hoc on the basis of the relationship between trials $n$ and $n-1$. Task alternation trials in the associatedbetween condition had two kinds of transitions: related and unrelated. If a subject had day and noun assigned to the high-low task and night and verb assigned to the odd-even

Table 2

Mean Reaction Times as a Function of Cuing Condition (Associated Within, Associated Between, and Unassociated), Transition (CR, Cue Repetition; TR, Task Repetition; and TA, Task Alternation), Stimulus Onset Asynchrony (SOA), and Intertrial Interval (ITI)

\begin{tabular}{|c|c|c|c|c|c|c|}
\hline \multirow[b]{2}{*}{ SOA } & \multicolumn{3}{|c|}{$300 \mathrm{msec}$} & \multicolumn{3}{|c|}{$900 \mathrm{msec}$} \\
\hline & CR & TR & TA & CR & TR & TA \\
\hline \multicolumn{7}{|c|}{ Associated Within } \\
\hline 0 & 1,026 & 1,204 & 1,359 & 1,109 & 1,245 & 1,327 \\
\hline 100 & 930 & 1,057 & 1,249 & 967 & 1,132 & 1,300 \\
\hline 300 & 808 & 967 & 1,128 & 841 & 1,002 & 1,171 \\
\hline 600 & 770 & 917 & 1,062 & 871 & 982 & 1,056 \\
\hline 900 & 785 & 895 & 1,019 & 843 & 926 & 1,029 \\
\hline \multicolumn{7}{|c|}{ Associated Between } \\
\hline 0 & 1,057 & 1,315 & 1,395 & 1,088 & 1,306 & 1,372 \\
\hline 100 & 919 & 1,256 & 1,285 & 1,021 & 1,218 & 1,344 \\
\hline 300 & 774 & 1,111 & 1,134 & 880 & 1,136 & 1,172 \\
\hline 600 & 767 & 998 & 1,068 & 818 & 965 & 1,061 \\
\hline 900 & 771 & 880 & 1,003 & 805 & 959 & 992 \\
\hline \multicolumn{7}{|c|}{ Unassociated } \\
\hline 0 & 983 & 1,233 & 1,333 & 1,070 & 1,237 & 1,342 \\
\hline 100 & 845 & 1,113 & 1,240 & 830 & 1,092 & 1,194 \\
\hline 300 & 809 & 996 & 1,125 & 830 & 1,092 & 1,102 \\
\hline 600 & 740 & 866 & 1,045 & 808 & 979 & 1,066 \\
\hline 900 & 757 & 876 & 931 & 804 & 890 & 1,025 \\
\hline
\end{tabular}


task, day $\rightarrow$ night would be a related task alternation, and noun $\rightarrow$ night would be an unrelated task alternation. Mean RTs were $1,174 \mathrm{msec}$ for related task alternations and 1,190 msec for unrelated task alternations. To test the significance of this difference, we conducted a 2 (transition: task alternation-related or task alternation-unrelated) $\times$ 5 (SOA: 0, 100, 300, 600, or $900 \mathrm{msec}) \times 2$ (ITI: 300 or $900 \mathrm{msec}$ ) ANOVA on the mean RTs for task alternation trials in the associated-between condition. The main effect of transition was not significant $\left[F(1,23)=1.75, M S_{\mathrm{e}}=\right.$ 18,135.15]; the interactions between transition and SOA $\left[F(4,92)=0.41, M S_{\mathrm{e}}=21,367.10\right]$, transition and ITI $\left[F(1,23)=1.20, M S_{\mathrm{e}}=20,274.03\right]$, and transition, SOA, and ITI $\left[F(4,92)=1.50, M S_{\mathrm{e}}=21,950.58\right]$ also were not significant. Consequently, we collapsed across related and unrelated task alternations in the associated-between condition for all the subsequent analyses. We will address the null effect of relatedness on task alternation RTs in the Discussion section.

Mean RTs and accuracy scores (percent correct) for each combination of transition, SOA, ITI, and cuing condition are presented in Tables 2 and 3, respectively. Table 4 contains the results of 3 (cuing condition: associated within, associated between, or unassociated) $\times 3$ (transition: cue repetition, task repetition, or task alternation) $\times 5(\mathrm{SOA}$ : $0,100,300,600$, or $900 \mathrm{msec}) \times 2$ (ITI: 300 or $900 \mathrm{msec}$ ) mixed factors ANOVAs on the RTs and accuracy scores, with cuing condition as a between-subjects factor and all other variables as within-subjects factors. Accuracy was high, averaging $95.9 \%$. The accuracy data were consistent with the RTs, and there was no suggestion of a speedaccuracy trade-off, so the analyses will focus on RT.

\section{RT Analysis}

The ANOVA in Table 4 indicates that mean RT increased significantly as ITI increased from 300 to $900 \mathrm{msec}$ ( $M \mathrm{~s}=1,012$ and 1,034 msec, respectively), and the tran-
Table 3

Mean Percentages of Correct Responses Across Subjects as a Function of Cuing Condition (Associated Within, Associated Between, and Unassociated), Transition (CR, Cue Repetition; TR, Task Repetition; and TA, Task Alternation), Stimulus Onset Asynchrony (SOA), and Intertrial Interval (ITI)

\begin{tabular}{|c|c|c|c|c|c|c|}
\hline \multirow[b]{2}{*}{ SOA } & \multicolumn{3}{|c|}{$300 \mathrm{msec}$} & \multicolumn{3}{|c|}{$900 \mathrm{msec}$} \\
\hline & $\mathrm{CR}$ & TR & TA & $\mathrm{CR}$ & TR & $\mathrm{TA}$ \\
\hline \multicolumn{7}{|c|}{ Associated Within } \\
\hline 0 & 97 & 96 & 94 & 97 & 95 & 94 \\
\hline 100 & 97 & 96 & 95 & 96 & 96 & 94 \\
\hline 300 & 97 & 96 & 94 & 98 & 96 & 94 \\
\hline 600 & 98 & 96 & 95 & 97 & 96 & 94 \\
\hline 900 & 97 & 98 & 95 & 97 & 97 & 95 \\
\hline \multicolumn{7}{|c|}{ Associated Between } \\
\hline 0 & 96 & 95 & 94 & 96 & 95 & 94 \\
\hline 100 & 98 & 95 & 95 & 96 & 96 & 95 \\
\hline 300 & 95 & 96 & 95 & 97 & 96 & 95 \\
\hline 600 & 98 & 96 & 95 & 97 & 97 & 95 \\
\hline 900 & 97 & 98 & 95 & 96 & 97 & 96 \\
\hline \multicolumn{7}{|c|}{ Unassociated } \\
\hline 0 & 94 & 92 & 89 & 95 & 91 & 88 \\
\hline 100 & 94 & 93 & 91 & 95 & 88 & 88 \\
\hline 300 & 91 & 96 & 89 & 95 & 91 & 87 \\
\hline 600 & 96 & 96 & 91 & 93 & 91 & 90 \\
\hline 900 & 96 & 91 & 94 & 95 & 91 & 93 \\
\hline
\end{tabular}

sition effects decreased significantly as ITI increased (the difference between cue repetitions and task alternations was $300 \mathrm{msec}$ at the $300-\mathrm{msec}$ ITI and $280 \mathrm{msec}$ at the 900-msec ITI). However, these effects were relatively minor, and the other variables in the ANOVA had similar effects at both ITIs (see Table 2), confirming the conclusion from previous experiments that SOA effects are not an artifact of the passage of time between responses to successive targets (Allport et al., 1994; for similar results, see Arrington \& Logan, 2004; Logan \& Bundesen, 2003; Mayr \& Kliegl, 2003; Meiran, 1996; Meiran et al., 2000).

Table 4

Summary Tables for ANOVAs on Mean Reaction Times (RTs) and Mean Percentages of Correct Responses $[P(C)]$

\begin{tabular}{|c|c|c|c|c|c|}
\hline \multirow[b]{2}{*}{ Source } & \multirow[b]{2}{*}{$d f$} & \multicolumn{2}{|c|}{ RT } & \multicolumn{2}{|c|}{$P(\mathrm{C})$} \\
\hline & & $M S_{\mathrm{e}}$ & $F$ & $M S_{\mathrm{e}}$ & $F$ \\
\hline Cuing condition $(\mathrm{C})$ & 2,69 & $1,200,540.88$ & 0.35 & 207.44 & 0.03 \\
\hline Transition (T) & 2,138 & $60,423.63$ & $230.32^{* *}$ & 23.61 & $43.69^{* *}$ \\
\hline $\mathrm{C} \times \mathrm{T}$ & 4,138 & $60,423.63$ & $2.36^{\dagger}$ & 23.61 & 0.37 \\
\hline $\mathrm{SOA}(\mathrm{S})$ & 4,276 & $20,065.83$ & $405.53^{* *}$ & 15.90 & $6.44^{* *}$ \\
\hline $\mathrm{C} \times \mathrm{S}$ & 8,276 & $20,065.83$ & $2.24^{*}$ & 15.90 & 0.40 \\
\hline $\mathrm{T} \times \mathrm{S}$ & 8,552 & $15,386.74$ & $8.95^{* *}$ & 15.95 & 0.54 \\
\hline $\mathrm{C} \times \mathrm{T} \times \mathrm{S}$ & 16,552 & $15,386.74$ & 0.96 & 15.95 & 1.17 \\
\hline ITI (I) & 1,69 & $24,311.13$ & $38.91^{* *}$ & 12.66 & 2.71 \\
\hline $\mathrm{C} \times \mathrm{I}$ & 2,69 & $24,311.13$ & 1.56 & 12.66 & 0.66 \\
\hline $\mathrm{T} \times \mathrm{I}$ & 2,138 & $16,930.00$ & $8.36^{* *}$ & 12.49 & 1.00 \\
\hline $\mathrm{S} \times \mathrm{I}$ & 4,276 & $15,330.12$ & 1.10 & 13.43 & 2.21 \\
\hline $\mathrm{C} \times \mathrm{T} \times \mathrm{I}$ & 4,138 & $16,930.00$ & 1.38 & 12.49 & 1.00 \\
\hline $\mathrm{C} \times \mathrm{S} \times \mathrm{I}$ & 8,276 & $15,330.12$ & 1.04 & 13.43 & 0.54 \\
\hline $\mathrm{T} \times \mathrm{S} \times \mathrm{I}$ & 8,552 & $15,414.75$ & 0.45 & 14.27 & 0.99 \\
\hline $\mathrm{C} \times \mathrm{T} \times \mathrm{S} \times \mathrm{I}$ & 16,552 & $15,414.75$ & 1.16 & 14.27 & 0.36 \\
\hline
\end{tabular}

Note $-d f$, degrees of freedom; $M S_{\mathrm{e}}$, mean squared error; SOA, stimulus onset asynchrony; ITI, intertrial interval. ${ }^{*} p<.05 .{ }^{* *} p<.01 . \quad{ }^{\dagger} p<.06$. 
Consequently, the RT analyses will focus on the effects of SOA, transition, and cuing condition, collapsed across ITI. The means across subjects are plotted as points in Figure 1 . The lines represent model predictions, which will be described below.

In each cuing condition, mean RT decreased significantly with SOA, replicating the standard time course function. Mean RTs were shorter for cue repetitions than for task alternations, and the difference decreased with SOA (i.e., the interaction between transition and SOA was significant; see Table 4), replicating the standard measure of switch cost and its reduction with preparation time. Mean RTs were shorter for cue repetitions $(M=$ $895 \mathrm{msec})$ than for task repetitions $(M=1,033 \mathrm{msec})$, suggesting an encoding benefit for repeated cues, and were shorter for task repetitions than for task alternations ( $M=1,175 \mathrm{msec}$ ), suggesting (to us) a priming effect for related cues and facilitation in mediator retrieval. Fisher's least significant difference (LSD) for $p<.05$, calculated from the error term for the main effect of transition, was $81 \mathrm{msec}$. By this criterion, each of the pairwise differences was significant.

The effects of cuing condition and their interactions with transition were the main theoretical focus of the experiment. Cuing condition had little effect on cue repetition trials $(M \mathrm{~s}=895,890$, and $913 \mathrm{msec}$ for associated-within, associated-between, and unassociated, respectively) or on task alternation trials $(M \mathrm{~s}=1,175,1,182$, and 1,217 $\mathrm{msec}$ for associated-within, associated-between, and unassociated, respectively), but it had strong effects on task repeti-

Associated Within
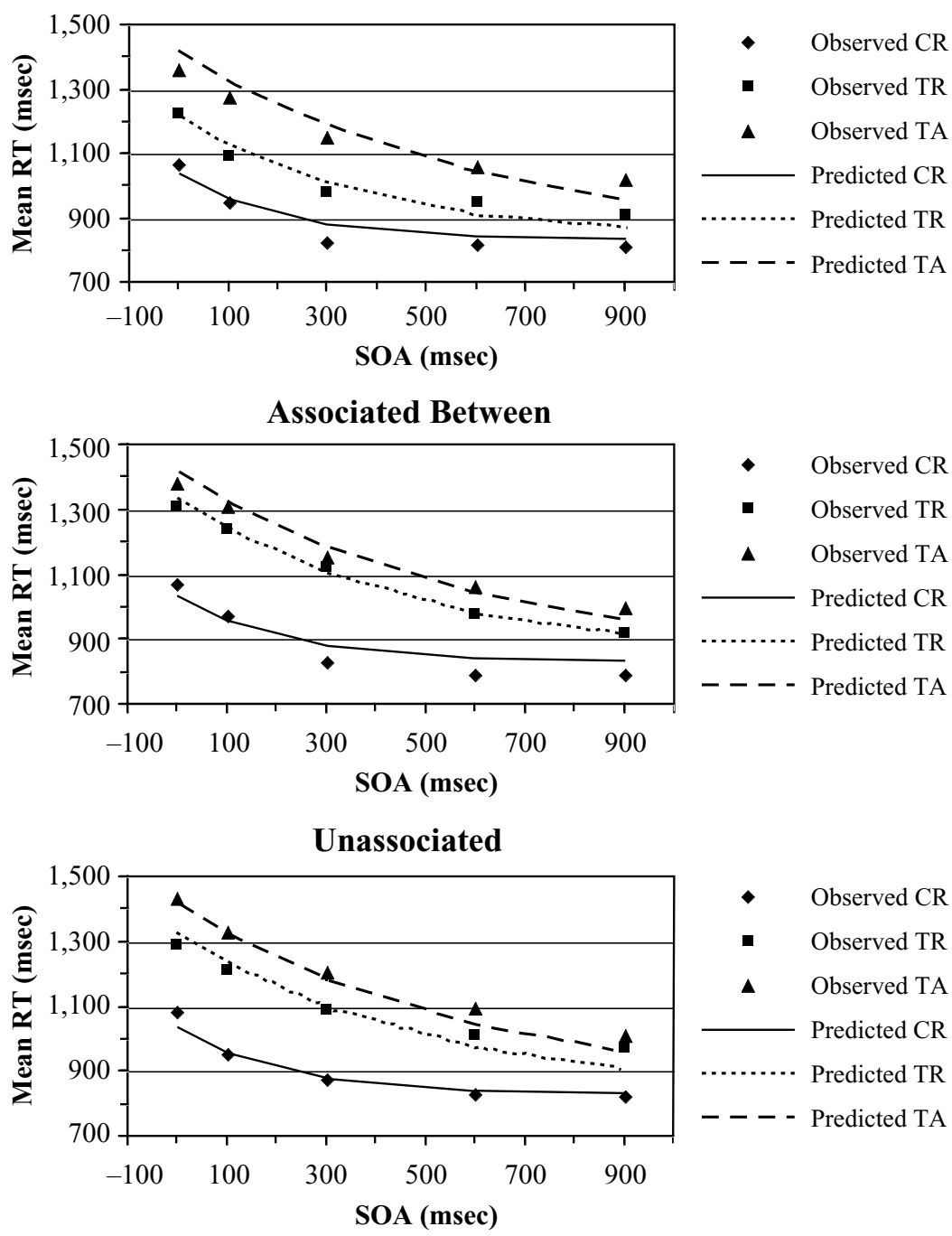

Figure 1. Mean reaction time (RT) in each cuing condition (associated within, associated between, and unassociated) for each transition (CR, cue repetition; $T R$, task repetition; and $\mathrm{TA}$, task alternation) as a function of stimulus onset asynchrony (SOA). Points represent observed data, and lines represent the predictions of the six-parameter model. 
tion trials, consistent with the predictions of the priming hypothesis. Mean RT was $1,033 \mathrm{msec}$ in the associated-within condition, $1,114 \mathrm{msec}$ in the associated-between condition, and $1,117 \mathrm{msec}$ in the unassociated condition. Fisher's LSD for $p<.05$, calculated from the error term for the interaction between transition and cuing condition, was $81 \mathrm{msec}$. By this criterion, there was no significant difference in cue repetitions between cuing conditions and no significant difference in task alternations between cuing conditions, but task repetitions were significantly faster in the associatedwithin condition than in the associated-between and unassociated conditions. This pattern suggests that there was semantic or associative priming among same-task cues in the associated-within condition that facilitated RT, relative to the unassociated condition. It also suggests there was no inhibition in the associated-between condition (Neely, 1991).

\section{Model Analyses}

Fits to data averaged across subjects. The analysis of mean RTs suggests that there was priming of cue encoding in the task repetition condition, but that analysis does not measure cue-encoding time directly or separate cue encoding from other factors, such as residual switch costs (Rogers \& Monsell, 1995) or differences in base RT. To estimate cue-encoding time and separate cue encoding from other factors, we modeled the time course functions, using Equation 1. The priming hypothesis predicts faster cue encoding (smaller values of $\mu$ ) for cue repetitions than for task repetitions, because priming from an identical cue (repetition priming) should be stronger than priming from an associated cue (associative or semantic priming). It predicts faster cue encoding for task repetitions than for task alternations, because task repetitions may benefit from associative or semantic priming. The priming hypothesis also makes predictions about the effects of cuing condition on cue-encoding times. It predicts no effect of cuing condition on cue-encoding times for cue repetitions and no effect of cuing condition on cue-encoding times for task alternations. However, for task repetitions, it predicts faster cue encoding in the associated-within condition than in the unassociated condition (facilitation) and, possibly, faster cue encoding in the unassociated condition than in the associated-between condition (inhibition).

These predictions suggest that the data from all three cuing conditions (45 points) will be fit by a six-parameter model derived from Equation 1, in which there is one base RT for all three cuing conditions, one cue-encoding time for all three cue repetition conditions, one cue-encoding time for all three task alternation conditions, but separate cue-encoding times for the three task repetition conditions. We fit this model to the mean RTs averaged over subjects, using the Solver routine in Microsoft Excel to minimize the root mean squared deviation (RMSD) between observed and predicted values. The six-parameter model fit the data well. The predicted values are plotted, along with the observed values, in Figure 1. The bestfitting parameters and measures of goodness of fit (RMSD and the product-moment correlation between observed and predicted values, $r$ ) are presented in Table 5. The parameter values are consistent with the priming hypothesis predictions: Cue-encoding time is shorter for cue repetitions than for task repetitions and shorter for task repetitions than for task alternations. For task repetitions, cue-encoding time is shorter for the associated-within condition than for the unassociated condition, reflecting facilitation from semantic or associative priming, and cue-encoding time is longer for the associated-between condition than for the unassociated condition, reflecting inhibition from semantic or associative priming.

We fit other models to the data averaged across subjects to test the necessity and sufficiency of the six-parameter model. To test necessity, we compared the six-parameter model with a four-parameter model in which there was only one cue-encoding time for the task repetition condition. If it is necessary to have separate cue-encoding times for each cuing condition in the task repetition condition, the six-parameter model should fit significantly better than the four-parameter model. The four-parameter model is nested within the six-parameter model, in that the six-parameter model is the same as the four-parameter model if the three cue-encoding time parameters for task repetitions have the same value, so it is possible to test the significance of the improvement in goodness of fit by comparing the correlations between observed and predicted values. The correlation for the six-parameter model (.982) was significantly larger than the correlation for the four-parameter model $(.972)[F(2,39)=10.36, p<.01]$, and RMSD was substantially smaller ( 34 vs. $42 \mathrm{msec}$ ). This indicates that it is necessary to have separate cue-encoding parameters for task repetitions in the three cuing conditions.

To test the sufficiency of the 6-parameter model, we compared its fit with that of a 12-parameter model, in which there was a separate cue-encoding time for each transition in each cuing condition and a separate base RT in each cuing condition. The 6-parameter model assumed a single cue-encoding time for cue repetitions for all three cuing conditions, a single cue encoding time for task alternations for all three cuing conditions, and a single base RT for all three cuing conditions. The 12-parameter model relaxed these assumptions, allowing separate parameters for each condition. If the assumptions are sufficient to describe the data, relaxing them will not improve the goodness of fit (i.e., the 12-parameter model will not fit significantly better than the 6-parameter model). The 6-parameter model is nested within the 12-parameter model, in that the 12-parameter model is identical to the 6-parameter model if cue-encoding times for cue repetitions and task alternations and base RTs are equal in all three cuing conditions, so it is possible to test the significance of the improvement in goodness of fit. The correlation between observed and predicted RTs was larger for the 12-parameter model (.986) than for the 6-parameter model (.982), but the difference was not significant $[F(6,33)=1.44, p=.23]$, and RMSD was not substantially smaller ( 30 vs. $34 \mathrm{msec}$ ). This indicates that the 6-parameter model is sufficient to describe 
Table 5

Values of Best-Fitting Parameters and Measures of Goodness of Fit for Model Fits to Mean Reaction Times for Group Data and Individual Subject Data

\begin{tabular}{|c|c|c|c|c|c|}
\hline & \multicolumn{3}{|c|}{ Group Data } & \multirow{2}{*}{\multicolumn{2}{|c|}{$\begin{array}{c}\text { Individual } \\
\text { Data } \\
(12 \\
\text { Parameters })\end{array}$}} \\
\hline & \multirow{2}{*}{$\begin{array}{c}4 \\
\text { Parameters } \\
\end{array}$} & \multirow{2}{*}{$\begin{array}{c}6 \\
\text { Parameters }\end{array}$} & \multirow{2}{*}{$\begin{array}{c}12 \\
\text { Parameters }\end{array}$} & & \\
\hline & & & & $M$ & $S E$ \\
\hline \multicolumn{6}{|l|}{ Parameter values } \\
\hline $\mathrm{RT}_{\text {Base }}$ & 832 & 832 & & & \\
\hline $\mathrm{RT}_{\text {Base-Within }}$ & & & 834 & 835 & 33 \\
\hline $\mathrm{RT}_{\text {Base-Between }}$ & & & 797 & 775 & 33 \\
\hline $\mathrm{RT}_{\text {Base-Unassociated }}$ & & & 852 & 830 & 37 \\
\hline$\mu_{\mathrm{CR}}$ & 209 & 209 & & & \\
\hline$\mu_{\mathrm{CR}-\text { Within }}$ & & & 186 & 191 & 17 \\
\hline$\mu_{\text {CR-Between }}$ & & & 246 & 266 & 17 \\
\hline$\mu_{\text {CR-Unassociated }}$ & & & 198 & 220 & 23 \\
\hline$\mu_{\mathrm{TR}}$ & 457 & & & & \\
\hline$\mu_{\text {TR-Within }}$ & & 381 & 366 & 371 & 26 \\
\hline$\mu_{\text {TR-Between }}$ & & 497 & 539 & 557 & 26 \\
\hline$\mu_{\text {TR-Unassociated }}$ & & 489 & 466 & 487 & 32 \\
\hline$\mu_{\mathrm{TA}}$ & 585 & 586 & & & \\
\hline$\mu_{\mathrm{TA}-\mathrm{Within}}$ & & & 548 & 555 & 28 \\
\hline$\mu_{\text {TA-Between }}$ & & & 616 & 630 & 28 \\
\hline$\mu_{\mathrm{TA} \text {-Unassociated }}$ & & & 595 & 615 & 32 \\
\hline \multicolumn{6}{|l|}{ Goodness of fit } \\
\hline$r$ & .972 & .982 & .986 & & \\
\hline$r_{\text {Within }}$ & & & & .908 & .012 \\
\hline$r_{\text {Between }}$ & & & & .894 & .012 \\
\hline $\begin{array}{l}r_{\text {Unassociated }} \\
\text { RMSD }\end{array}$ & & & & .893 & .012 \\
\hline RMSD & 42 & 34 & 30 & & \\
\hline $\mathrm{RMSD}_{\text {Within }}$ & & & & 71 & 4 \\
\hline RMSD $_{\text {Between }}$ & & & & 76 & 4 \\
\hline $\mathrm{RMSD}_{\text {Unassociated }}$ & & & & 73 & 4 \\
\hline
\end{tabular}

the data. The assumptions about equal base RTs and equal cue-encoding times for cue repetitions and task alternations appear to be warranted.

Fits to individual subject data. We also tested the predictions of the priming hypothesis by fitting the model to data from individual subjects. We fit a 4-parameter model to each subject's data, allowing a separate cueencoding time for cue repetitions, task repetitions, and task alternations while requiring a common base RT for all three conditions. Cuing condition was manipulated between subjects, so the three cuing conditions were fit separately. Consequently, 12 parameters were required to describe the whole experimental design, 4 from each of the three groups of subjects. The mean parameter values and their standard errors are presented in Table 5, along with measures of goodness of fit. The 4-parameter models fit the individual subject data reasonably well. The correlations were lower than those for the fits to the data averaged across subjects, and the RMSDs were larger, but the individual subject data were a lot less stable than the data averaged across subjects. The parameter values from the 12-parameter fit to the data averaged across subjects are presented in Table 5 for comparison. There was good agreement between the fits to the individual subjects and the fit averaged across subjects. All of the parameters from the fit to the average data fell within the $95 \%$ confidence intervals of the mean parameter values from the fits to individual subjects.

The mean values of the parameters confirmed the predictions of the priming hypothesis. The differences in cueencoding times between the three cuing conditions were small for cue repetitions and task alternations but large for task repetitions. The differences in base RT were small as well. We tested the significance of these differences by subjecting the parameter values to one-way ANOVAs with cuing condition as the single factor. These ANOVAs revealed no significant effects of cuing condition on cue encoding time for cue repetitions $\left[F(2,69)=2.32, M S_{\mathrm{e}}=\right.$ $14,697.74, p=.11]$ or task alternations $[F(2,71)=0.72$, $\left.M S_{\mathrm{e}}=37,098.49, p=.49\right]$ and no significant effects of cuing condition on base RT $\left[F(2,69)=1.43, M S_{\mathrm{e}}=\right.$ $40,029.10, p=.25]$. However, cuing condition had significant effects on cue-encoding times for task repetitions $\left[F(2,69)=6.77, M S_{\mathrm{e}}=26,812.90, p<.01\right]$. 


\section{DISCUSSION}

The experiment reproduced standard switch cost effects in the task-switching literature. RT was shorter when tasks repeated than when they alternated, and the difference decreased as SOA increased. The design of the experiment allowed us to evaluate the contribution of cue-encoding benefits to these switch costs. Mean RT was shorter for cue repetitions than for task repetitions, corroborating previous findings that show that cue encoding can benefit from repetition priming (Arrington \& Logan, 2004; Logan \& Bundesen, 2003, 2004; Mayr \& Kliegl, 2003; Schneider $\&$ Logan, 2005). The novel contribution was to demonstrate cue-encoding benefits from semantic or associative priming for task repetitions, in which the cue changed but the task stayed the same. For these transitions, cue encoding was faster if successive cues were semantically or associatively related than if they were unrelated. We demonstrated semantic or associative priming of cue encoding in analyses of mean RTs and in fits of the models based on our priming hypothesis to the time course functions.

The results are important because they extend the domain of the compound stimulus strategy or compound retrieval cue strategy described in previous research (Arrington \& Logan, 2004; Logan \& Bundesen, 2003, 2004). Previous discussions of these strategies have addressed repetition priming from identical cues in cue repetition conditions but have not addressed semantic or associative priming from related cues. Consequently, they have been unable to explain differences between task repetitions and task alternations that have been observed repeatedly in the literature, even with meaningful word cues (but see Schneider \& Logan, 2005). The present results suggest that those differences can be interpreted in terms of semantic or associative priming between related cues, which would occur for task repetitions but not for task alternations. Indeed, procedures that use two meaningful word cues for each task necessarily introduce semantic or associative relations between cues in task repetitions. Otherwise, the two meaningful cues could not refer to the same task.

We do not believe that priming from related cues explains all of the difference between task repetitions and task alternations in the present experiment. Although the cues were words, their conventional meanings bore no relation to the tasks to be performed on the targets, so an additional retrieval process must have been engaged before the targets could be processed appropriately. Following Logan and Bundesen (2004), we suggest that the subjects used the cues to retrieve mediators-possibly, task names - that they combined with the targets to form compound retrieval cues, which pulled the appropriate responses from memory. The time required to retrieve the mediator may contribute to the differences between transitions. With cue repetitions, mediator retrieval may not be necessary. Subjects may recognize that the current cue is the same as the previous one and decide to use the mediator from the last trial, which should still be active in working memory. With task repetitions, the subjects would have to retrieve the mediator, but retrieval may be speeded by the presence of an identical mediator from the last trial in working memory. With task alternations, the subjects would have to retrieve the mediator, and retrieval may be impaired by the presence of a different mediator from the previous trial in working memory, or it may be unaffected. Thus, mediator repetition speeds mediator retrieval in cue repetition and task repetition trials, but not in task alternation trials. Some of the difference between task repetition and task alternation trials may be due to facilitated mediator retrieval, and some may be due to semantic or associative priming from related cues.

It is not clear why there was no significant difference between related and unrelated cues for task alternations in the associated-between condition. On the one hand, the semantic relation between cues should have sped up cue encoding. On the other hand, the related cues were associated with different tasks, so they would have activated different mediators, and that may have slowed mediator retrieval. The slowing of mediator retrieval may have balanced the speeding of cue encoding, resulting in a net difference between related and unrelated cues that was not significant. Future research will be required to evaluate this possibility.

Perhaps the fact that the present results can be explained in terms of priming and mediator retrieval should not be surprising. Both the parity and the magnitude tasks used in our experiment can be solved by retrieval from semantic memory. The subjects could compute parity by dividing the target digit by two and examining the remainder, and they could compute magnitude by subtracting five from the target digit and examining the sign of the difference, but it seems more likely that they simply remembered the parity and magnitude of each digit. The size and origin (living vs. nonliving) tasks in Arrington and Logan's (2004) experiment can also be solved by retrieval from semantic memory. Other tasks may be solved by retrieval from episodic memories acquired during practice or early in the experiment. Mayr and Kliegl (2003) had subjects classify a small set of familiar colors (red, green, blue) and forms (circle, square, triangle) that they knew before the experiment began. Semantic memory would provide the task-relevant classification; episodic memory would provide the required response (i.e., which key to press). In each case, memory retrieval seems sufficient, and reconfiguration seems unnecessary. Memory retrieval requires the same task set no matter what the task is: encode the cue, encode the target, put them together to form a retrieval cue, and respond with what they pull from memory. There is no need to reconfigure this task set from one trial to the next.

Retrieval from semantic or episodic memory may be the core process underlying most of the tasks that are studied in the task-switching literature. Tasks with arbitrary cues and arbitrary responses may require additional retrieval processes. Arbitrary cues require retrieval of a mediator until subjects have had enough experience to form direct associations between cues, targets, and responses. Arbitrary responses must also be retrieved after the task-relevant clas- 
sification has been retrieved. For example, our experiment required subjects to press the 1 key to indicate $o d d$. After retrieving odd as a response, given odd-even (retrieved using an arbitrary cue) and 7 as a target, they would then have to retrieve 1 as the way to express odd in the context of the experiment. These additional retrieval processes are not different in kind from the semantic and episodic retrieval processes that are at the core of task performance. As with the core processes, these additional retrieval processes work in the same way on each trial, regardless of the task, and so do not need to be reconfigured.

Models based on priming and memory retrieval provide good accounts of performance in task-switching experiments, providing detailed explanations of the underlying computations in terms of well-understood processes (see Schneider \& Logan, 2005). In our view, the onus is on proponents of reconfiguration to provide similarly detailed, quantitative accounts of the computations underlying performance. In order to explain why reconfiguration is necessary, they must explain how the system is configured to perform a particular task and how that configuration is different from the one required to perform another task (Logan \& Gordon, 2001). Then they must explain the computations involved in creating a configuration and the computations involved in changing a configuration. And they must generate predictions that uniquely identify the processes they propose that cannot be accounted for by priming and memory retrieval.

\section{REFERENCES}

Allport, A., Styles, E. A., \& Hsien, S. (1994). Shifting intentional set: Exploring the dynamic control of tasks. In C. Umiltà \& M. Moscovitch (Eds.), Attention and performance XV: Conscious and nonconscious information processing (pp. 421-452). Cambridge, MA: MIT Press, Bradford Books.

Allport, A., \& Wylie, G. (2000). Task switching, stimulus-response bindings, and negative priming. In S. Monsell \& J. Driver (Eds.), Control of cognitive processes: Attention and performance XVIII (pp. 3570). Cambridge, MA: MIT Press.
Arrington, C. M., \& Logan, G. D. (2004). Episodic and semantic components of the compound-stimulus strategy in the explicit taskcuing procedure. Memory \& Cognition, 32, 965-978.

Logan, G. D., \& Bundesen, C. (2003). Clever homunculus: Is there an endogenous act of control in the explicit task-cuing procedure? Journal of Experimental Psychology: Human Perception \& Performance, 29, 575-599.

Logan, G. D., \& Bundesen, C. (2004). Very clever homunculus: Compound stimulus strategies for the explicit task-cuing procedure. $P s y$ chonomic Bulletin \& Review, 11, 832-840.

LogAn, G. D., \& GoRdon, R. D. (2001). Executive control of visual attention in dual-task situations. Psychological Review, 108, 393-434.

Logan, G. D., \& ZBrodoff, N. J. (1982). Constraints on strategy construction in a speeded discrimination task. Journal of Experimental Psychology: Human Perception \& Performance, 8, 502-520.

MaYr, U., \& KLIEGL, R. (2003). Differential effects of cue changes and task changes on task-set selection costs. Journal of Experimental Psychology: Learning, Memory, \& Cognition, 29, 362-372.

MeIRAN, N. (1996). Reconfiguration of processing mode prior to task performance. Journal of Experimental Psychology: Learning, Memory, \& Cognition, 22, 1423-1442.

Meiran, N., Chorev, Z., \& SaPir, A. (2000). Component processes in task switching. Cognitive Psychology, 41, 211-253.

NeELy, J. H. (1991). Semantic priming effects in visual word recognition: A selective review of current findings and theories. In D. Besner $\&$ G. Humphreys (Eds.), Basic processes in reading: Visual word recognition (pp. 264-336). Hillsdale, NJ: Erlbaum.

Nelson, D. L., McEvoy, C. L., \& SchreIBer, T. A. (1999). The University of South Florida word association, rhyme, and fragment norms. Retrieved February 5, 2004 from w3.usf.edu/FreeAssociation/.

Rogers, R. D., \& Monsell, S. (1995). Costs of a predictable switch between simple cognitive tasks. Journal of Experimental Psychology: General, 124, 207-231.

SchneIDER, D. W., \& Logan, G. D. (2005). Modeling task switching without switching tasks: A short-term priming account of explicitly cued performance. Journal of Experimental Psychology: General, 134, 343-367.

Waszak, F., Hommel, B., \& Allport, A. (2003). Task-switching and long-term priming: Role of episodic stimulus-task bindings in taskshift costs. Cognitive Psychology, 46, 361-413.

WaszaK, F., Hommel, B., \& Allport, A. (2004). Semantic generalization of stimulus-task bindings. Psychonomic Bulletin \& Review, 11, 1027-1033.

(Manuscript received November 7, 2004; revision accepted for publication June 9, 2005.) 